\title{
QUANDO O LÍRICO E O NARRATIVO SE ENCONTRAM EM NUNO JÚDICE
}

\author{
Maria Heloísa Martins Dias \\ (Unesp/São José do Rio Preto)
}

\section{RESUMO}

A poesia de Nuno Júdice singulariza-se pela natureza híbrida de seu discurso, cujos procedimentos de construção entretecem poesia e prosa, apagando as fronteiras rígidas entre os modos lírico e narrativo, por isso mesmo fugindo de moldes classificatórios. Embora a tradição clássica seja uma referência e se faça presente na carga imagética e alegórica da figuração mítica, em muitas poesias, a modernidade desfaz as demarcações nítidas entre os tempos e os espaços, ao impulsionar o texto a dobrar-se sobre si mesmo em suas reflexões acerca dos processos que alimentam o corpo poético, feito simultaneamente de canto e logos, concretude e abstração. Seu livro As Regras da Perspectiva, de 1990, torna visível essa tendência para a interpenetração de prosa e poesia, de que extraímos dois poemas para serem objeto de nossa análise. Nessa peculiar textualidade, a metalinguagem é uma das faces a interagir com outras, entre elas, a textura das sensações, a ocultação do eu lírico, a narratividade, o mistério dos sentidos, as formas do mundo.

PALAVRAS-CHAVE: Nuno Júdice, As Regras da Perspectiva, gêneros literários.

\begin{abstract}
Nuno Judice'poetry has a peculiar discourse, whose devices of construction mixe poetry and prose in order to eliminate the borders between the two kinds of language. The Classical tradition is a constant reference in his poetry, by means of the imagery and the allegory in which some Greek myths are mentioned. Nevertheless, the context of modernity from which the poet Nuno Judice emerges put together the dimensions of space and time so as it is impossible to separate them. In this paper we analyse two poems extracted from the book As Regras da Perspectiva (1990) and our purpose is to discuss some literary questions as the metalanguage, the sensations, the lyric subjectivity, the narrative trends, the special meanings and the forms of the world.
\end{abstract}

KEYWORDS: Nuno Júdice, As Regras da Perspectiva, literary genres. 
Mais do que uma bizarra excrescência da árvore genealógica literária, o poema em prosa é uma problematização das Raízes da própria história literária.

Barbara Johnson

É de 1990, o livro As Regras da Perspectiva, de Nuno Júdice, foco de nosso interesse e de que tomaremos dois poemas para servirem aos nossos comentários críticos. Comecemos com o que se intitula "Costumes":

O deus lúgubre ensina o caminho: "Para além das árvores, dos montes, depois de atravessar a planície, o lago, os mares de ondas estagnadas, e aquele muro de palavras que nenhuma sibila interpretou." Nem todos conseguiram entender esta direção; e perderam-se logo ali, no lugar em que os caminhos se bifurcam. "Quem foi o cego que nos trouxe aqui?”, perguntam. E sentam-se, exaustos, nas pedras do largo. No entanto, os pássaros prosseguem um rumo que eles próprios poderiam adivinhar. $\mathrm{O}$ horizonte nada tem de secreto, nem de obscuro, e sob as palavras incompreensíveis crescem outras frases, que o poema arranca da terra. Então, levantai os olhos do chão; segui com a vista o vôo desses enxames, para que uma intuição de movimento vos desperte; $\mathrm{e}$ deixai o centro, a luz, o sol morto do outono, para entrardes na água abstrata da vida cujo murmúrio faz ouvir o canto invisível do verso. (JÚDICE, 1990, p. 17-18)

O livro se compõe de 38 poemas, cuja textualidade se faz da mescla de poesia e prosa, objeto de nossa discussão. No caso do texto em questão, por meio de quais procedimentos estéticos se configura esse tecido híbrido de linguagens? Que efeitos de sentido se engendram nessa configuração? Como o leitor se comporta diante dessa não-demarcação de limites entre um gênero e outro?

Talvez seja interessante começarmos pelo título, o qual nos oferece uma referência, "costumes", que nos leva a pensar em algumas possibilidades, como tradição ou valores culturais. Tradição formal, memória literária, espaço de cultura, momento histórico, hábitos de comportamento e de pensamento, mitos - todo esse material, dentre outros, fica implícito no signo que emoldura o poema e, de certa forma, deixa-nos uma margem de expectativa em relação a esses elementos.

Entretanto, ao olharmos para o texto, para sua corporalidade gráfico-espacial, algo desponta de seu aspecto visual: o texto vai-se recortando livremente, com frases de desigual medida, com sinais de pontuação variáveis ao longo desse corpo textual formado de um só bloco com dezenove linhas. Trata-se de um versilibrismo, tendência que eclodiu já no final do século XIX com os simbolistas franceses (Gustave Kahn, René Ghil, Jean Moréas, Verhaeren), na linha mallarmeana, e que um poeta como 
Whitman incorporaria efusivamente, na primeira metade do século XX. Porém, ao contrário do movimento impulsivo das sensações e emoções whitmanianas, o verso livre no poema de Nuno Júdice tem a sua liberdade serenada por pausas, por paragens, em meio às quais o discurso repousa, se pensa, indaga. No poeta português, portanto, a libertação da métrica, do ritmo e rimas, de esquemas de regularidade, soltando o verso das convenções estritas, não atende ao ímpeto revolucionário, até porque distante desses momentos de rebeldia programática. O propósito de Júdice está mais em afinidade com aquilo que Alfredo Bosi ponderou sobre a liberdade moderna de ritmos e a mobilidade no arranjo da frase. Segundo o crítico, tal tendência corresponde a uma consciência de que é possível aplicar na prática do poema o princípio duplo da linguagem, de ser simultaneamente sensorial e discursiva, finita e aberta, cíclica e vetorial (BOSI, 1977, p. 76).

Parece-nos que, qualquer que seja o teor dos "costumes" a ser abordado pelo poema, deixado em suspenso pelo título, o poeta posiciona sua linguagem de modo a desequilibrar o que seria estável, cômodo ou costumeiro, para lançar seu texto em uma aventura marcada pelo imprevisível. Nem verso, nem prosa, mas uma linguagem que se isenta do que seria (e qual seria?) o caminho certo ou pré-estabelecido de um e de outro gênero, como se ouvindo sua própria voz e comando, e não as de uma tradição.

Seria uma espécie de "canto invisível do verso", como lemos no final do poema? Ou uma fala que se torna visível justamente porque elide os limites entre prosa e verso? É preciso examinar melhor o texto para compreender o que há nessa (in)visibilidade.

$\mathrm{O}$ texto se inicia com a referência a um deus, motivo caro à literatura de todos os tempos, quer estejamos pensando ou não no contexto mitológico que poderia lhe dar sustentação. Mas, quem conhece outros textos do poeta Júdice, sabe que o referencial clássico é neles uma moldura constante, muito presente. A esse propósito, Ida Ferreira Alves já comentara sobre "a importância da cultura clássica na formação do poeta" (ALVES, 2001, p. 166), daí a presença de mitos gregos em sua poesia, em especial Narciso, Orfeu, Perséfone.

E, se nossa leitura for acertada, estamos diante de uma situação arquetípica: ouvir o ensinamento de uma voz sábia, profética, diante de um dilema. A fala se enuncia, por meio da citação, e seu conteúdo é tão enigmático quanto o deus lúgubre que a profere, pois a indicação do caminho se marca por passagens que parecem não ter fim; espaços e mais espaços que terminam num mistério: "aquele muro de palavras que nenhuma sibila/ interpretou."

Para além da célebre cena em que Édipo se depara com a esfinge, símbolo máximo desse enfrentamento do sujeito com o desconhecido em busca de sua decifração, o que nos interessa não é o mito propriamente, mas os elementos que figuram no poema para construír a imagem da indefinição de caminhos, de seus caminhos. Ou seja, o repertório mitológico constitui um pré-texto que o texto presente transforma em realidade de linguagem que se autorreflete, construindo seus próprios enigmas e buscando saídas para o labirinto em que está mergulhada. Portanto, o poema vai-se fazendo como essa travessia que, mesmo tendo consultado o Saber (que não lhe esclarece sobre os verdadeiros caminhos), segue sua própria rota, armado de sua intuição e aberto aos riscos dessa aventura. Notemos, 
nesse caso, que não há a nomeação do deus, ele é apenas lúgubre, mas sem rosto nem especificações. Ser lúgubre já é um sinal de seu obscurecimento ou de sua não presença plena, como se coubesse à linguagem, situada em seu espaço de precariedade, existir por sua conta e risco, ouvindo e não ouvindo as palavras proféticas.

Se nenhuma sibila interpretou o sentido das palavras que se erguiam como um muro diante dos caminhantes (versos $4,5,6$ ), sendo-lhes impossível seguir a direção indicada, o poeta segue em seu percurso pelo poema, não temendo perder-se como os outros, pois sua consciência crítica o orienta, ainda que seja para o imprevisto. Essa espécie de metalinguagem engenhada sob o véu dos referentes mitológicos é interessante como tática poética. É que, desse modo, os elementos presentes nos versos, como "caminho(s)", "atravessar", "direção", "muro de palavras", bem como os nomes alusivos ao espaço natural ("árvores", "montes", "planície”, "lago", "mares de ondas"), acabam funcionando como metáforas do próprio texto, espaço a ser percorrido e decifrado pelo eu lírico.

No verso sétimo, a pergunta que parte da voz coletiva colocada em cena pelo poeta - "Quem foi o cego/ que nos trouxe aqui?" - tem um duplo efeito. Num primeiro momento, podemos pensar em mais uma referência à fonte mitológica, contida na figura do cego, afinal, a cegueira aliada ao saber profético e às adivinhas é comum nos mitos gregos (o adivinho Tirésias, de Tebas, por exemplo, personagem da Odisséia, de Homero). Por outro lado, a indagação soa também como um pôr em causa, pelo viés irônico e crítico, a própria ignorância (cegueira) presente, como se guiados por uma inconsciência (alienação?) que então se reconhece como inútil. Isto é, a essa altura do caminhar e já distantes da misteriosa orientação recebida (um além não decifrado por nenhuma sibila), os sujeitos só têm o presente incerto como direção.

De qualquer modo, é curiosa essa coexistência de tempos, o da tradição grega e o da visão derrisória moderna, como se fossem duas faces de Jano a impedirem a afirmação exclusiva de apenas um lado. Seja como consulta a algum oráculo, seja como um caminho às cegas motivado pela ousadia dos próprios sujeitos, o resultado é insatisfatório, já que não leva, literalmente, a lugar algum.

Nesse ponto cabe considerarmos a presença de procedimentos que deslocam o poético para o funcionamento da prosa. Há uma situação em foco (uma travessia), verbos que enunciam as ações, falas de personagens, alusões espaciais, enfim, o texto vai-se movendo por uma narratividade caracterizada pelo contar. E um contar que se faz por uma sintagmática em que se destaca uma cadeia cronológica, um antes e um depois: o "ensinar" do caminho, o não entendimento, o caminhar, a perda, o cansaço, a parada. Portanto, há uma certa linearidade, característica da prosa, no entanto, trata-se de um contar que se reveste de certo ritualismo, marcado justamente pelas pausas, o que nos poderia levar a pensar que, embora não haja métrica regular, o tom solene, elevado, da linguagem, nos reporta ao canto arcaico, cujos passos, "recitados ou cantados, deviam ser escandidos com energia ritual" (BOSI, 1977, p.70): "E sentam-se, / exaustos, nas pedras do largo." ( versos 8 e 9): uma sílaba tônica, duas sílabas breves em palavras nucleares, demarcando a solenidade do gesto. Desse modo, o eu-lírico narrador é uma instância que incorpora ao mesmo tempo as funções de vate (o antigo profeta ou bardo), oculto no "deus lúgubre" que inicia ou 
sopra o início desse canto poético, e de poeta contemporâneo, enunciador de uma linguagem que rompe com as barreiras entre o verso e a prosa, o canto e o discurso, ao mesmo tempo falando e pensando sobre esse falar.

A partir do nono verso, o texto poético se marca por outro momento, inaugurado pelo "No entanto" (mais um índice do teor narrativo), quando uma nova imagem - os pássaros - seguem seu próprio rumo, impulsionados por sua natureza intuitiva para a qual não há segredos no horizonte nem no espaço a ser percorrido. É o momento em que as "palavras" ressurgem no poema (verso 12) nomeadas, porém, como corpo em liberdade, diversamente do início em que figuravam como fala do deus. Ainda que incompreensíveis, as palavras adquirem movimento e se organizam num voo ou espaço liberto de amarras, onde "crescem outras frases, que o poema arranca/ da terra." (versos 13 e 14). Notemos como, pela metalinguagem, a força do dizer busca seus caminhos em meio aos limites que o cercam, rompendo raízes, oferecendo-se como linguagem que traz em seu corpo as potencialidades de sentido a serem decifradas. É como se o (in) compreensível fosse tramando o seu próprio percurso, tornando possível ao leitor enfrentá-lo. Se não é mais possível ouvir uma voz originária ou detentora de Saber, como a poesia moderna nos revela, então essa voz deve ser buscada em seu próprio espaço, ainda que precário. É o que diz Alfredo Bosi, com outras palavras acerca desse novo ofício do poeta moderno: “A divindade para a qual se movia o canto mítico esconde o rosto, eclipsada pelos ídolos das novas ideologias, enquanto se mantém o fervor da devoção, votado agora ao ofício de escrever.” (BOSI, 1977, p. 82)

De fato, a poesia não é destituída de fervor. Mas essa paixão não se manifesta na presença explícita do eu lírico, agora recuado para um pano de fundo ou subtraído da cena para dar relevo ao ser da linguagem; nem se manifesta na exposição de sentidos conhecidos, menos ainda na oferta de uma essência colhida de tempos imemoriais. É, antes, uma paixão em cumplicidade com o indizível, em que o sujeito lírico só se reconhece na materialidade da palavra, a falar e a ouvir sua própria voz.

E aí topamos com o último movimento do poema, levados pelo "Então", do décimo quarto verso. Nesse momento a linguagem poética assume nova forma discursiva, pois o eu lírico se dirige a um "vós", identidade indefinida e múltipla, para fazer uma súplica. Resgatando o papel do poeta como aquele que fala em nome do antigo sábio profeta, seu pedido aponta para o rumo a ser seguido por aqueles que desejam acompanhar as palavras aladas escritas em seu poema. Por isso, o "vós" pode se identificar com os leitores, a seguirem os enxames-palavras, então descondicionados de convenções e amarras. Despertada pela intuição de movimento, a leitura deve flagrar esse gesto ambíguo da fala mitopoética ${ }^{1}$, ao mesmo tempo enlaçada ao mito e atenta ao tempo presente: o da palavra pensada, construída pelo seu próprio fazer. A consciência do poeta moderno não lhe permite incorporar o mito sem a mediação da distância espácio-temporal; por isso, a fala oracular não pode figurar como absoluta ou como realidade encerrada em si mesma, ela se complementa com o teor discursivo que transforma o mythos em logos, o (en)canto em reflexão. É o que o poema de Júdice nos oferece, especialmente na liberdade de sua forma.

Hesitante entre a devoção e a autonomia, a linguagem poética de Júdice reflete aquela contradição de que nos fala Octavio Paz ao comentar sobre a poesia moderna, como se evidencia em seu livro A Outra 
Voz. Encarnando uma modernidade que luta consigo mesma, "desgarrada entre a revolução e a religião, vacilante entre chorar como Heráclito e rir como Demócrito" (PAZ, 1993, p. 142), a poesia se faz como transgressão, ou, ainda segundo o dizer de Paz, ela "não cessou de ser uma pertinaz e teimosa heterodoxia." (PAZ, 1993, p.139). Tensionada entre a dívida para com o passado arcaico (por isso os elementos mitológicos?) e sua história presente, atenta a uma "outra voz", exterior e longínqua, e fazendo aflorar a sua própria, consciente dos caminhos que se bifurcam (como enuncia o sétimo verso), a poesia de Júdice só poderia se estruturar como esse embate entre o contínuo e o corte, os sons e o pensamento, o caminho para diante e o retorno, o verso e a prosa.

Seguir o que a voz do poeta nos aconselha, ao final de seu poema, significa voltar nosso olhar não para as coisas concretas e naturais, como "o centro, a luz, o sol morto do outono" (antepenúltimo verso), e sim penetrarmos na abstração que somente a palavra poética pode construir com "o canto invisível do verso", eis como termina o poema. O que estaria sugerindo a metáfora "água abstrata da vida" em que devemos entrar, segundo o poeta, senão a natureza singular da escrita, esse fluxo ou líquido que se condensa e se torna abstrato em suas figurações de sentido? Perpassada pelo invisível, mas palpável pela materialidade de seus signos percorrendo livremente os caminhos da página, fazendo-se como um dis-curso, a linguagem pode, enfim, sair do labirinto ou escapar do enigma que lhe fora colocado inicialmente pelo "deus lúgubre" do primeiro verso. Não há nenhum caminho além, nem é mais preciso alguma sibila para interpretar o sentido ou sugeri-lo por enigmas, pois a palavra encontrou em si mesma o percurso que procurava.

Digamos que tal percurso poético é feito menos de um investimento nas potencialidades sonoras e musicais da palavra do que nas imagens, o que corresponderia à fanopéia, segundo a categorização de Ezra Pound sobre as modalidades de poesia ${ }^{2}$. Desse modo, embora o poema esteja ligado ao mítico, sua "fala" não é musical nem apegada aos esquemas regulares do verso, mas, antes, é uma fala imagética, que extrai do mitológico as figuras para redimensioná-las à luz da modernidade, recontextualizando-as, ou, pensando em Genétte, operando uma transtextualização ${ }^{3}$. Assim como outros poemas de Nuno Júdice, "Costumes" aproxima-se do alegórico, não por expor uma "cena alegórica" (aliás, título de outro poema de seu livro As Regras da Perspectiva), mas pelo simbólico contido na "narrativa" presente no texto, em que despontam elementos alusivos ao mítico.

Por outro lado, seria exagero afirmar que o elemento sonoro está ausente do poema "Costumes", pois em seu final, quando do voo das palavras, levantadas da raiz/chão da página, o movimento aliterativo em /v/ vai traçando o percurso do canto: "levantai"/ "vista"/ "vôo"/ "movimento"/ "vos"/ "vida"/ "ouvir"/ "invisível"/ "verso".

Talvez fosse útil aproveitarmos a sugestão contida no título da obra de Júdice. Afinal, "regras" e "perspectiva" são dois signos fundamentais para compor o universo que o livro configura com sua escrita singular: a perspectiva não é senão essa mobilidade posta no olhar para projetar ou traçar seu foco em direções cujas regras não obedecem necessariamente a visões pré-estabelecidas. Caminhos que se bifurcam, uma intuição do movimento, seguir o voo são expressões presentes no poema "Costumes" e 
que materializam o traçado livre do poema em busca de sua forma possível. Aqui caberia uma rápida incursão por aquilo que esse poema deixa implícito como indagação para o leitor, em função de sua estrutura: estaríamos diante de um poema em prosa? Responder a isso demandaria um caminho longo e denso de reflexões, que foge a nosso propósito; no entanto, o poema nos convida a certo posicionamento em relação a essa questão. Vejamos.

Barbara Johnson (1982), autora citada na epígrafe a este texto, tem um interessante artigo sobre os problemas da relação entre prosa e poesia. Em "Algumas conseqüências da diferença anatômica dos textos. Para uma teoria do poema em prosa" Johnson, estabelece uma comparação entre dois textos de Baudelaire, o poema "La chevelure" e o texto em prosa "Un hémisphère dans une chevelure", que não queremos trazer aqui para discutir, pois nosso objeto é outro. No entanto, há considerações de Johnson que nos servem como aporte para nossas reflexões.

Um dos aspectos contidos nessa discussão é a conotação negativa que cerca o poema em prosa quanto a seu estatuto. Não pertencer a gêneros específicos, portanto, colocando em causa o sistema (classificatório?) para se afirmar como diferença ou oscilação, acentua sua natureza problemática, fato instigante, e não algo negativo, como às vezes é visto, uma espécie de "hibridismo monstruoso". Conforme nos diz Johnson, "o bilhete de identidade do poema em prosa lê-se como um catálogo de anomalias de descendência."(JOHNSON, 1982, p. 113)

Em vez de uma preocupação com a expressão em si e com seus efeitos enquanto classificação textual, parece-nos que o mais profícuo do ponto de vista crítico é pensar nessa configuração textual, conforme sugere a estudiosa americana, como um espaço em que "a polaridade - e, portanto, a simetria - entre presença e ausência, entre prosa e poesia, disfunciona." (JOHNSON, 1982, p. 118). Disfuncionar significa deixar de ter sentido a busca de uma unidade entre ambos os gêneros, tanto quanto a insistência na sua oposição. Trata-se, antes, de perceber que o que singulariza o poema em prosa não é o fato de ele se afastar da especificidade de uma e de outra linguagem, e sim o fato de que sua natureza se tece no interior da própria distância, fazendo-se como processo autoconstitutivo e modificador, quer dos traços da poesia, quer dos traços da prosa.

Nesse sentido, não deveríamos ver o texto de Nuno Júdice como poema em prosa, mas sim como um poema (versos) que incorpora a prosa (narratividade) em seu corpo para acentuar o funcionamento poético, independentemente da origem específica das duas linguagens. Por isso, a "fala" que emerge de seu texto é poética, não porque se estruture em versos, mas porque se abre a margens que incorporam elementos ou registros diversos: mito, narrativa, alegoria, metalinguagem. Esses fios, ampliando a espacialização estrófica e entrecruzando-se como vozes para a feitura do poema, conferem a ele sua significação maior.

Por outro lado, devemos considerar as reflexões do próprio Júdice sobre poesia, pois a preocupação em definir um campo para o poético perpassa toda a sua obra, entendendo-se este como o universo temático que a poesia comporta, ou como as formas que estruturam a materialidade de sua linguagem ${ }^{4}$. Evidencia-se, ao longo de As Regras da Perspectiva, o percurso do sujeito lírico em busca da natureza constitutiva do poema, o que transparece nos textos "Alegoria", "Poema", "Estio", "Principio de retórica", 
"Lira", "O louco", "Canção", "Poética”. Digamos que essa recorrência pode indiciar, afinal, a consciência da impossibilidade de se estabelecer com nitidez e rigor o âmbito especifico do poético - instância de linguagem em que ser e não-ser buscam-se como pulsões não disjuntivas do dizer. Vejamos o "Poema", um dos quatro textos com esse mesmo titulo, o segundo que figura em seu livro:

Esqueci-me de quem sou. Um rumo de oráculos entontece as nuvens. O verso não refere as indecisões do poeta, nem o céu, que o outono manchou de sangue, se afasta de um ritmo azul. No canto, ambos se juntam: o branco de uma espuma que o naufrágio contamina; $\mathrm{e}$ os cinzentos da superfície, desafiando um sol que não rompe o temporal. No fundo, um mastro, quase que o horizonte o esconde. Uma lógica de asas o dirige para essa margem que exclui o regresso. Por instantes, hesito na própria sequência do raciocínio: procurar, nos átrios da memória, o corredor de um vago infinito; ou prosseguir a descida indicada num charco de sombras? Depois, quando ouço o riso que o abismo logo abafa, ouso a escolha do inicio. O nome impede, a quem interroga os lábios ocultos, que uma resposta se ouça. (JÚDICE, 1990, p. 33)

A perda da identidade, motivo que nos reporta à poesia pessoana, abre o poema de Júdice, como se o verso nos alertasse, de saída, para a estranha natureza do "Poema", uma escrita subtraída da identidade lírica e como que já instituindo uma errância feita dos deslizes e lapsos desse esquecimento: "Esqueci-me de quem sou". Portanto, ao constatar o apagamento de sua natureza ontológica, a voz lírica legitima a abertura para um rumo de incerteza que só mesmo a aventura das imagens poderá construir como matéria poética.

Novamente a tradição clássica está presente, na menção aos oráculos (segundo verso), cujos poderes não se dirigem a seres humanos e sim às nuvens, entontecendo-as. Num primeiro momento, poderíamos pensar no sopro enigmático da fala oracular como capaz, assim, de desnortear o espaço natural; porém, o que temos no verso é "rumo de oráculos" e não ruídos ou o som de suas falas, o que reforça o efeito de estranhamento provocado pela linguagem. $\mathrm{O}$ desnorteamento das nuvens atuaria, nesse sentido, como correlativo objetivo ${ }^{5}$ do estado do sujeito lírico, um jogo metafórico para sugerir uma correspondência entre o eu e o mundo, aproximando-se a poesia dos propósitos simbolistas, na esteira de Baudelaire. Não por acaso, o Simbolismo é uma das raízes de que se alimenta a poesia de Nuno Júdice. Voltando à sensação do entontecer, lembremos que no outro poema, "Costumes", concretiza-se essa mesma imagem de desorientação, como apontamos anteriormente.

Ao ler uma passagem como "O verso/não refere as indecisões do poeta” e projetar esses versos para o momento posterior do poema em que lemos "Por instantes, hesito/ na própria sequência do raciocínio;", estamos 
diante de uma contradição, a qual poderia se resolver se pensássemos que o poeta estaria incorporando ou materializando em seu discurso aquela imagem do entontecer das nuvens. Na verdade, o verso não se refere $a$, mas sim realiza o que diz, pois a hesitação do poeta não é objeto do dizer e sim o seu próprio fazer; a sua vacilação entre as imagens do mundo e as da própria palavra poética corporifica-se na escrita, não no dito, mas na performance imagética. É isso que nos propõem os versos: " $\alpha$ branco de uma espuma que o naufrágio contamina; e/ os cinzentos da superfície, desafiando um soV que não rompe o temporal." O poético se instala nessa dinâmica ou tensão entre superfície e profundidade, o branco e o cinzento, a espuma que se abisma e o temporal abrandado pelo sol, enfim, vida e morte. Entre a proposta de junção ("No canto, ambos se juntam:") e a separação instaurada pela sintaxe por meio do ponto-e-vírgula, distanciando o branco dos cinzentos.

Ao aceitar o desafio lançado pela via metalinguística que o poema encena nesse jogo tensional como constitutivo do poético, poderemos ver/er na "espuma", aludida no sexto verso, o desfazer dos sentidos esperados ou cristalizados, que se aprofundam, ocultando outras virtualidades que a leitura deve desocultar; assim como o "naufrágio" é metáfora do mergulho de que poeta e leitor não escapam em seu contato com a palavra. Não há como ficar na superfície quando tudo nos impele a uma estrutura profunda, a única que nos poderá fornecer os elementos mobilizadores da tensão entre a forma e o sentido, ou, nos termos propostos por Hyelmslev, entre os planos da expressão e do conteúdo, uma dinâmica mais complexa do que a simples dicotomia entre forma e sentido ${ }^{6}$. No canto proposto por Júdice, esses movimentos de queda ou imersão, de elevação ou emersão são fundamentais para compor os sentidos de sua poesia. Sob a forma interrogativa, esses impulsos se projetam como possibilidades: "procurar,/ nos átrios da memória, o corredor de um vago/ infinito; ou prosseguir a descida indicada num charco de sombras?" Aqui parece ecoar aquele "rumo de oráculos" do início do poema, atuando ainda como fala desorientadora que leva o poeta (o que esqueceu quem é) a se interrogar, em busca de um caminho a seguir.

A presença da memória se faz como uma linha isotópica constante na poesia de Nuno Júdice. Enquanto "arte da memória", conforme nos revela a análise de Alves (2001, p.139-180), essa poesia dialoga com a dimensão temporal, porém, fundindo-a a outras esferas, em especial a da espacialização da própria linguagem poética. A oscilação entre "o corredor de um vago/ infinito" (versos 13 e 14) e um "charco de sombras" (verso 15) revela-nos que o espaço da palavra a ser definido pelo poeta não tem limites, como exibem os próprios versos em sua variação métrica e rítmica. Tal como acontece no outro poema já analisado, em "Poema" também a oscilação entre cortes e encadeamentos, brevidade e extensão, materializa em sua textura o jogo entre o infinito e a parada. Horizontalidade e verticalidade.

Em sua composição imagética o poema também desenha esse jogo entre profundidade e superfície, o vertical e o horizontal, sugerido pelas metáforas do mastro e das asas (versos 8 a 11). Mas, é preciso ressaltar, não se trata de mera dualidade e sim de uma construção entrecruzada de contradições: o mastro não se mostra por inteiro, assim como as asas são dotadas de uma lógica que impede sua total liberdade. Dessa forma, tanto o mastro esconde sua referencialidade e função orientadoras como as asas 
não se aventuram ao acaso e sim dirigem o mastro para uma margem sem regresso. Seja como for, o que resulta dessas imagens contraditórias é uma concepção poética que descarta o contornável ou o acesso imediato aos sentidos, preferindo, antes, o caminho do abismo e dos atalhos difíceis.

Defrontando-se com tais desafios, o poeta se permite fazer sua escolha. Já distante do entontecer que aludira no começo de seu poema, e conhecendo o abismo que o assedia, ele sabe que a palavra, ou melhor, o nome não conduzirá a um caminho seguro ou a uma resposta, porque a interrogação se dirige a "lábios ocultos" (oráculos com rumos enigmáticos?). Por isso, ao ouvir o riso abafado pelo abismo, a sua escolha é pela consciência que o leva a abrir mão da certeza e da resposta: "ouço o riso/ que o abismo logo abafa, ouso a escolha/ do início." (versos 15 a 17). Notemos como o jogo sonoro criado entre os signos procura driblar o riso (índice de ironia?) que vem, não sabemos exatamente de onde, se dos oráculos, se do próprio espaço natural. Assim: ouço/ouso, riso/abismo, ouço/início; a ditongação em ouço o riso, que o abismo, logo abafa, ouso a escolha, do início. Enfim, contra a adversidade do real o poeta ousa opor a força de sua materialidade poética. Daí que a sua "escolha/ do início", como afirma, não pode ser entendida como regresso ou desistência, nem como uma subserviência aos oráculos que o desatinam ou lhe fazem perder a identidade; antes, essa escolha revela o conhecimento dos poderes, ainda que hesitantes, da poesia para construir-se como linguagem.

Como vimos, a leitura dos poemas de Nuno Júdice contidos em As Regras da Perspectiva sugere interessantes questões para a literatura, em especial a problemática das relações entre prosa e poesia enquanto interfaces da trama textual.

\section{Notas}

1 O termo, utilizado por Alfredo Bosi, em seu livro O ser e o tempo da poesia, refere-se ao modo historicamente possível de existência da poesia moderna enquanto resistência à sociedade tecnológica: "a fala mitopoética deplora as úlceras que o dinheiro fez e faz na paisagem (...) e tenta reviver a grandeza heroica e sagrada dos tempos originários, unindo lenda e poema, mythos e epos." (1977, p.149).

2 A fanopéia, assim como a melopéia e a logopéia aparecem comentadas em seu $A b c d a$ literatura, cuja apresentação “As Antenas de Ezra Pound”, escrita por Augusto de Campos, também traz comentários sobre esses conceitos.

$3 \mathrm{O}$ termo transtextualidade, assim como outros correspondentes a uma minuciosa categorização genettiana sobre o texto, estão em seu livro Introduction à l'Architexte. Paris, 1979.

4 Nos termos de T.S. Eliot, o correlativo objetivo se define como um meio de se expressar emoção em arte, segundo o qual "um conjunto de objetos, uma situação, uma cadeia de acontecimentos constituirá a fórmula daquela emoção particular, de tal modo que, quando ocorrerem fatos exteriores, que devem culminar numa experiência sensorial, a emoção seja imediatamente evocada.". Tal noção foi colocada por Eliot em seu ensaio "Hamlet e seus problemas", recolhido em Selected Essays.

5 Conforme reconhece Ida Ferreira Alves, em seu artigo já citado, a condição do poeta a refletir sobre o próprio processo de criação e sobre sua existência como poeta está presente em muitos momentos da obra poética de Júdice, o que vem ao encontro de uma das tendências do discurso estético-critico contemporâneo, ao se questionar sobre o estatuto da própria arte. (Alves, 2001, p.145-146).

6 Estou me referindo às noções postuladas por Hyelmslev em sua obra Prolegômenos de uma teoria da linguagem. 


\section{REFERÊNCIAS BIBLIOGRÁFICAS}

ALVES, Ida Maria Santos Ferreira. A poesia de Nuno Júdice: arte da memória. Revista da ABRAPLIP - Memória e Identidade. Santa Maria, n 2, p.139-180, 2001.

BOSI, Alfredo. O Ser e o Tempo da Poesia. São Paulo: Cultrix/Edusp, 1977. HJELMSLEV, Louis. Teoria de uma teoria da linguagem. 2. ed. São Paulo: Perspectiva, 2009.

JOHNSON, Barbara. Algumas conseqüências da diferença anatômica dos textos. O Discurso da poesia. Coimbra: Almedina, p.111-136, 1982.

JÚDICE, Nuno. As Regras da Perspectiva. Lisboa: Quetzal, 1990.

PAZ, Octavio. A Outra Voz. São Paulo: Siciliano, 1993.

POUND, Ezra. Abc da Literatura. São Paulo: Cultrix, 1989.

ELIOT, T.S. Selected Essays: 1917-1932. Faber\& Faber, 1932.

(Recebido para publicação em 14/11/2010

Aprovado em 12/12/2010) 